\title{
CLARIFICATIONS REGARDING MEDICAL TOURISM DESTINATION MARKETING
}

\author{
Aurelia-Felicia Stăncioiu 1*, Andreea Botoş ${ }^{1}$, Ion Pârgaru ${ }^{2}$
}

1 The Bucharest University of Economic Studies

2. Politehnica University, Bucharest

stancioiufelicia@hotmail.com

\begin{abstract}
The development of new types of tourism (stand-alone, connected or components), from marketing experience, implies a broad spectrum of challenges, which, placed in a planned background, has the purpose the creation and then, the development of tourism products that correspond, at least, to consumers' expectations. In order to optimize the new type of tourism, it is necessary to be correlated with the relevant resources of the destination, which, harmonized, can lead to the elaboration of destination marketing strategies, in this situation being the medical tourism, component of health tourism.

Key-words: health tourism, medical tourism, medical tourism destination marketing
\end{abstract}

JEL Classification: M3; L83.

\section{INTRODUCTION}

Travelling with a health-related purpose, with a practice since the third millennium $\mathrm{BC}$, has achieved, during time, to materialize, from a marketing perspective, a new type of tourism - the medical tourism. In its actual form, it has appeared as a consequence of a "rapid growth of an industry where people travel often long distances to benefit from medical, dental and surgical services while also being tourists in the conventional sense" (Connell, 2006). Practiced nowadays, it implies a high degree of complexity, both in structure and content, the availability, accessibility, familiarity and perceived quality influencing the spectrum of medical tourism (Connell, 2011; Laugesen \& Vargas- Bustamante, 2010). Involving, in its current form, many sectors (e.g., health, tourism, insurance etc.), whose development should take place in the same direction, for the synergy of the desired effects in terms of competitiveness, the development of a value chain that acts as "well-calibrated" mechanism is vital, especially as the patient's health is a "constant" for all tourism products in this area, affecting and, in turn, being affected by all other tourist activities around which it revolves.

\section{Conceptual framework}

Although the term "medical" is used to illustrate the concepts of illness/disease, disorder or injury (Jagyasi, 2008), most experts consider medical tourism as an umbrella term, i.e. an umbrella type of tourism, in which the improvement of health is a key component of a journey which involves invasive procedures, not passive processes on health, such as those practiced in wellness tourism (after Connell, 2013, p.2). This sense, perpetuated in that medical tourism has grown in contemporary society, has created tourist flows oriented by the selection criteria of potential consumers, but also by their resources, and has developed as a result of "high cost of treatment in 'rich' countries, too long waiting lists, affordability of air transport, favourable exchange rate, population aging, increasing interest in cosmetic surgery, procedures such as rhinoplasty, liposuction, etc., and certain medical services, e.g., dental services, not being covered by health insurance (available only in certain countries)" Connell (2006). Also, its development was based on a set of conditions favourable for the development of the phenomenon, starting from the many players involved in the microenvironment 
(e.g., healthcare providers, financial services providers, consumers), and the forces of the macroenvironment (e.g., demographics and legislation).

Although medical tourism refers, according to a recent definition in an integrative manner, to "a holiday involving travel abroad to obtain a wide range of medical services which may include leisure, fun and relaxation, and wellness or health services" (Heung, Kucukusta \& Song, 2010, quoted in Connell, 2013, p. 2), most definitions emphasise either the medical side or the tourism side of the product offered to the consumer by such combined services.

Thus, some notions emphasise the medical sphere, such as the maintenance, improvement or recovery of wellbeing (Carrera \& Bridges, 2006), improvement of health (Bookman \& Bookman, 2007), mobilisation of patients by their own will (Lunt \& Carrera, 2010) and benefitting from medical services (Cormany \& Baloglu, 2011). The emphasis on the tourism side, which gives meaning to the term "medical tourism", distinguishing it from "travel for medical purposes", is presented in the literature as involving a holiday in the conventional sense, outside of medical care (Connell, 2006), by the direct connection to leisure, business or other private purposes (Jagyasi, 2008) or by combining tourism with medical treatment (Jenner, 2008). Therefore, to create some tourism products that meet a destination's specificity where consumers will live the actual tourism experience, medical activities and, in this sense, those in conjunction with tourism activities which can be practiced depending on the general and tourism infrastructure are, in this way, carefully studied.

Such a combined approach can only be achieved through a process of marketing planning, acting in a shared environment (characterised by multiple opportunities and threats) influencing to varying degrees the different components of the medical tourism product, but acting as a "binder" of all creative forces. As medical tourism (as well as any type of tourism) cannot develop sustainably and, in terms of marketing, in a self-contained manner, being inextricably linked, among others, to the destination, and to all stakeholders, respectively, a systemic approach is required, observing the rules imposed by the conceptual nature of notions composing it. In this context, from the perspective of medical tourism destination marketing, several issues are raised that have as starting point the very definitions of tourism destination and medical tourism, which is why it was considered appropriate, for clarification, the parallel between type of tourism and medical tourism-destination, as "development" framework that provides a perspective on the relevant theoretical market.

Thus, the literature emphasises the complexity and diversity of medical tourism components (those related to "the body's health") to the detriment of those related to lifestyle (Stolley and Watson, 2012); note, in a broader sense, cosmetic surgery, dentistry, cardiac surgery, orthopaedics, bariatrics, reproductive systems, organ, cell and tissue transplantation, eye surgery, diagnosis and consultation (Lunt, 2011), or, in a narrower sense, cosmetic surgery, dentistry, cardiology, orthopaedic surgery (Lee, Balaban, 2013). Recognised as a "dimension of health tourism" in relation with all its other components, medical tourism, viewed in a systemic manner, can be deployed on two axes, namely: therapeutic, involving rehabilitation, healing and recovery, and surgical, involving cosmetic surgery, dental surgery and operations; in conjunction with wellness tourism, we can distinguish between therapeutic recreation programs, rehabilitation, occupational wellness, thalassotherapy, and detoxification and nutrition (Smith, Puckzo, 2009).

The complexity of the concept, especially its somewhat non-uniform 
definition, in the literature of this type of tourism, especially in the tourism destination, is a source of possible confusion and misunderstanding.

Therefore, delineating the area of practice of medical tourism (with consideration of destination specific components) should be an "axiom" to all its supporters, as a proper conceptual delimitation involves an overlap or perfect complementarity of axes related to the medical, tourism, geographic, safety area, support pillars of the sui generis product of "medical tourism". Moreover, the construction of tourism products must follow a path of "marketing understanding" of the phenomenon, through appropriate marketing tools, aiming at the conceptual definition of all concepts involved, and areas of interest (e.g., the concept of destination, medical tourism, etc.) with the delimitation of the interest area for the tourism type in question, analyzing the supply and demand for medical tourism products and the motivation from which they are derived. Following this information, it is advisable to carry out the audit of a destination for medical tourism, and to set goals and strategies - conditions for the development of this type of tourism.

Defined as the geographic place or space where a visitor or tourist stops either for an overnight stay or for a period of time or the end point of the tourists' holiday, whether they travel for business or tourism purposes, the destination involves, among others, "a coordinating organisational structure, legislation and specific regulations of government agencies, but also a mix of supporters of tourism, who support or make a marketing effort, being able to influence the existing image in the minds of tourists" (after Morrison, 2013). Using destination resources sustainably and competitively, its supporters' task is to turn attractions and facilities in positive experiences for own tourists. They can transcend the temporal boundaries of the actual consumption of the tourism product offering "after-sales services" in accordance with the nature of the product, their role being especially important in medical tourism, since health is a "desirable continuum". and the demand for health can always be regarded as "latent" for medical tourism, in the context of either an action for prevention, treatment, or recovery of health.

A medical tourism destination, whose profile has to be studied as it primarily influences the type of medical experience provided to the consumer, can be a tourist resort - locality or part of a locality with a tourist heritage and infrastructure (after the Tourism Law), a balneotherapy resort which has natural therapeutic or climatic resources, scientifically proven and recognised for their curative effect, which provides treatment, recovery or prevention services for diseases by providing balneotherapy medical care in appropriate conditions (after the Tourism Law), or any other destination whose infrastructure also allows the development of medical tourism.

Starting from the premise that medical tourism is a type of tourism that involves tourist movement for a "medical attraction" located in a tourism destination, we can note the inefficiency of a sequential or unilateral approach in which medical tourism is strictly analysed from the perspective of the type of tourism. Thus, medical tourism, viewed in the context of what a tourist can "receive" according to his needs and desires, is a result of an equation with three "unknowns" (or variables), namely type of tourism, tourism product and tourism destination. Since the elements considered are interdependent, the related combinations can generate many cases rendered by the specificities of each element considered, and involve a myriad of options for tourism products. As an incomplete combination can generate incomplete experiences, and therefore inconsistent with the expectations of consumers, medical tourism destination 
cannot be taken out of the destination, or, in other words, the development of new products including the component "medical tourism" must take into account the specificity of all the destination's resources (natural, anthropic, human, information and infrastructure).

Therefore, the type of tourism "medical tourism" (the "skeleton" on which medical tourism products are developed) must be regarded primarily as a framework necessary to develop specific procedures (e.g., cardiology, cosmetics, surgery, orthopaedics, transplantation, etc.) during the trip. They must observe regulations and rules specific to Romania (the EU, respectively), and must also take into account the regulations and rules specific to potential tourists' home states. Also, the development of medical tourism in health tourism is necessary to create a common denominator of all medical tourism products.

Another problem for destination marketing is the demand for medical tourism services, modelled either by the needs or desires of the consumer in a welldelineated and strengthened market, as these may conflict (e.g., the need to undergo a highly complex operation in a certain destination, and the desire to visit all cultural sights, etc., in that destination). This distinction between the rational and the emotional side of the consumer is more pronounced in the case of medical tourism, where the trip's motivation may be intrinsic (e.g., the consumer's own desire to improve his/her health), but also extrinsic (e.g., physician's advice). Therefore, solving the inner conflict generated in the consumer's psyche falls to marketers who need to identify the optimal solution for fulfilling both the needs and desires of the consumer, given that the development of medical tourism products, the set of regulations, rules and rigors most often do not allow compromises.

Also, in developing the tourism product for medical tourism, the potential tourist's motivation is found most often in the expected benefit, to be implemented as essence of the medical tourism product, according to needs. Given the double valence of medical tourism (with the two sides : medical and tourism), the medical product may be developed in two ways. In the first case, the medical product is the essence of the tourism product in a tourism destination (e.g., resort, balneotherapy) or locality (Figure 1).

Thus, the essence of the product is the treatment/improvement of a disease or recovery following a particular disorder, achievable in a balneotherapy resort, this being, in fact, the benefit perceived by consumers. Tangibilisation, in this case, can be achieved through the use of medical (consumer specific) and tourism (destination specific) services starting from the tourist and balneotherapy resort resources. The developed product may contain auxiliary services which complete the tourist experience, but which must be consistent with medical experience, without neglecting the pre- and postoperational part. Therefore, the development of medical products requires cooperation between all players in the value chain involved in their creation (e.g., healthcare providers, recreational, financial, insurance services providers, etc.).

A second situation appears where the medical product is not the essence of the tourism product (this constituting itself with balneotherapy resources within the balneotherapy resorts), but belongs to the developed product, a situation involving two possibilities: a) the medical motivation may be secondary but planned in the purchase decision-making process with a role in the tourism destination choice ; b) the medical motivation can occur spontaneously ("in situ"), due to unforeseen events. The essence of the product, in this case, often aims relaxation, recreation and rest (these activities generally being consistent with the requirements of a medical intervention of any kind), but there may be other main 
motivations, such as practicing sports, adventure, business, visiting relatives or friends, etc. All the elements of the tourism product in these situations should especially be harmonised in order to avoid situations of total dissatisfaction (e.g., not only failing to improve health, but even worsening it).

The same distinction can also be made in the case of tourism destinations for urban tourism (where, due to the existence of medical centres, medical products can be developed). In this case (Figure 2), we can emphasise the presence in the developed product of cultural services and events.

A tourism destination for medical tourism is where resources (those that can contribute to the development of health services, and others, regardless of the specificity) may be used by supporters of medical tourism to create medical products. For this, the most important condition for a medical destination indicates the existence of a health infrastructure (e.g., material base provision of equipment necessary for medical interventions, treatments, etc., and human resources - skills, abilities, etc.). Also, its resources should enable the development of tourist services, other than medical activities, to integrate and complete the medical experience with a tourist experience. Both components, both the medical and the tourist one, can differentiate the destination depending on the target market. While medical services within a tourism destination can be differentiated by their specificity and perceived quality level (leading to the development of the image of the healthcare facility and/or destination), tourism services have a wider range of resources and component processes that allow a wider room for manoeuvre, likely to differentiate a destination, using criteria such as the diversity of attractions, accessibility, and specificity of activities undertaken.
All these resources and services (medical, tourism and synergistic, but also those outlining the specificity of other types of tourism in the destination) render the very specificity of the medical tourism destination, and, by identification and differentiation, represent prerequisites for the medical tourism destination brand. It is important to consider all destination resources, which are similarly significant, even if not directly involved in the development of medical products, as they may influence the overall image of the destination, on the one hand, and may contribute to the medical tourism experience, on the other hand, in the context of the micro-destination. Adding an approach in terms of macro-destination can contribute positively to each microdestination relevant to medical tourism, similarly to shock waves carrying energy (in this case, the action of the umbrellabrand capital to the micro-destination brand), propagating in an environment (on the position in consumers' minds). If the macro-destination is positioned in the minds of consumers as a destination for medical tourism, the benefits to the umbrella-brand can increase the credibility of each micro-destination for practicing medical tourism.

As the forces, and thus the objectives of all medical tourism supporters are unevenly distributed, to build a unified tourism product we need to properly manage the tree structure in its value chain.

The first step in medical tourism marketing planning, but also the ultimate objective, is the imperative condition that Romania be a credible destination for medical tourism (Constantin, A., 2014); its actual specific tourism infrastructure is not sufficient, as it also needs to be realised by the target audience. In this respect, not only the understanding of medical tourism should be taken into account, but also Romania's position as a destination for medical tourism in the minds of consumers, with the inclusion of 
personality, values inspired by it and associations it entails. Therefore, the credibility of Romania regarding the destination for medical tourism may lie in strengthening some of its features, which are consistent with the rigors of medical tourism considered by consumers.

The supply and demand analysis for medical tourism in Romania is another issue for marketing planning. In the process of building a medical tourism product, along with the medical act (which automatically involves, in turn, the medical infrastructure and the competent human resources), the state of healthcare facilities in Romania (Table 1) represents "the certainty" from which the marketing specialist should start. You cannot assign an absolute value on hospitals, pharmacies, balneotherapy sanatoria, as their shortage or oversizing in tourism destinations depends on the size of the target segments that firstly take into account the specificity of the facility or the result of the analysis/market positioning. However, the large number of dental practices $(12,613$ in 2011) and family medicine practices $(11,211$ in the same year) represents an indicator worth taking into account for the size of the medical supply.

Also, the number of healthcare professionals representatives (Table 2), the number of medical staff $(125,992$ in 2011) and auxiliary staff $(60,130$ in 2011) give confidence on the size of the theoretical offer, while some data, and the evidence of quality, specialisation and experience of the medical staff, respectively, can even shape comparative advantages for Romania to develop medical tourism.

In terms of demand, there are not many studies on its structure and features, most being resumed to simple and strict medical polls, which analyse, at country level, the structure and the categories of patients (existing or treated) with different conditions. These data, although extremely useful, also for assessing the general health status of a population of a country, do not provide sufficient clues on the size of the medical tourism phenomenon, since not all patients with diseases classified will travel for medical purposes to meet their medical needs (touristically) and "consume" tourist activities. Also, not all actual consumers of medical products are registered in official statistics found in each country, as the need for such products can have an intrinsic source, not related to a diagnosis made by healthcare professionals (e.g., satisfying the need for medical tourism, in which the medical component contains cosmetic surgery or self-imposed or optional nutrition programs). Therefore, the true extent of the demand for medical tourism is difficult to identify, an opinion shared by some experts in Romania, who state that "no one knows the precise size of the medical tourism market [... ]" (Forna, N., 2014). Unfortunately, unlike other types of tourism, in terms of medical tourism, without precisely knowing the segments within it, we cannot create/develop medical tourism products.

The destination audit, an essential step in marketing planning, involves identifying all the resources of the macrodestination Romania and of its component micro-destination (e.g., balneotherapy resorts, tourist resorts, etc.), followed by combining them according to the needs and preferences of consumers, subject to the rigors of practicing medical tourism. In this context, the destination must be regarded as a unitary whole, so the use of all relevant and potential resources for medical tourism have a role in shaping the "medical (tourism) identity".

The opinion of target segments on resources, attractions, facilities, products, and tourism experiences, either based on a previous consumption or based on consulting different sources of information, is also important. Identifying how the destination is perceived in relation to a potential medical tourism statute must be compared by the marketer with the tourism and/or medical reality of the destination, as the differences can generate effects (negative or false positive effects) leading 
to the unsustainable development of the destination towards medical tourism. Thus the medical tourism market oversizing should not be encouraged and used by marketers to create tourism products, given that their promises cannot be backed by the reality of processes in the value chain! A positive image that cannot be supported (therefore, false) generates more significant subsequent damage, encouraging expectations too high on the destination and its products, affecting the trust and reputation of all its supporters. The two coordinates (trust and reputation) are extremely important in the art of marketing for the retention and loyalty of consumers; however, for medical tourism marketing, they are conditions without which there can be no tourism products that meet consumer needs. This can be explained by the fact that, most times, the stakes in terms of consumption of medical tourism products is even greater as it directly involves health, and therefore life, and the quality of life. Under these conditions, consumer demands may exacerbate, the trust and reputation of medical tourism brands having a significant role for the choice of medical tourism products or for renewing the promises associated with them. Therefore, identifying the "real identity" of the medical potential of a medical and/or tourism destination, and, subsequently, correctly communicating the benefits to consumers in order to obtain "an accurate, authentic image" are the main objectives of destination marketing.

Establishing the predominant type of tourism, developed as part of the destination in question, is another precursor stage to developing tourism products. It has to be established, and, subsequently, to take into account the fact that each destination most often allows the practice of multiple types of tourism, including those related to health. It is necessary for medical tourism as a type of umbrella-tourism, and, at the same time, as a niche within health tourism, to be defined in relation to health tourism or balneotherapy tourism, and also integrated, to the extent possible, with other types of tourism specific to the destination studied. The possibility of practicing self-contained medical tourism combined with balneotherapy tourism or all its components (including the wellness component) in the practice of health tourism (Figure 3) represents strategic options with a role in positioning the destination for medical tourism, using the positive effects of the systemic approach of health tourism.

Market analysis is the next important step in medical tourism marketing planning, a stage in which, using all relevant criteria, marketers must first make a process of segmentation. In the literature, the main criteria refer to the general motivation and the relationship with the main components of medical tourism, differentiating between: tourists under treatment, receiving treatment following accidents or medical problems occurred during a holiday abroad, medical tourists, visiting a particular country for medical treatment, patients on vacation, visiting destinations mainly for medical purposes, but using holiday facilities, especially during convalescence, and ordinary patients who visit based strictly on medical treatment and do not use holiday facilities (Cohen, 2008). Other segmentation criteria disseminated also in literature refer to income level and geographic location or origin, differentiating between: elite patients travelling for medical treatment at a high price, affluent patients travelling especially for cosmetic procedures, diaspora patients returning to their home country for political, economic, cultural and health reasons, foreign patients seeking cheaper, faster, culturally sensitive, and trustworthy medical services, and medical tourists travelling with a considerable personal cost for services unavailable in their country (Connell, 2013). Another segmentation proposed by Stolley and Watson (2012) 
associates medical tourism products consumers with different categories, such as: the uninsured, the hopeful, the random, the travellers, those interested in healthcare, the luxury seekers, the expatriates, those with high-income, lowincome and the informed, adding to the previously used criteria consumer interests and other psychographic characteristics.

After the segmentation, marketers must target those segments whose characteristics and requirements can be met by medical tourism products (existing or potential), and then to endeavour to correctly position them, in line with the "real" features "of the medical tourism product/products" of a particular destination. The tasks arising from this stage converge in knowing the potential consumer in relation to the three elements considered essential - type of medical tourism, the so-called "medical" destination, and implicitly the medical tourism product. In this context involving basically information, impressions, knowledge, ideas, consumer choices more or less modelled from personal experience (or not), to study the needs and wishes of medical tourists it is necessary to consider some key-elements used by marketers based on the existence in each destination of own standards, costs and specific areas of expertise. Efforts are therefore directed to studies that clarify the features of medical tourism marketing and show how safe the destination is considered, how much confidence can tourists have in the medical staff practicing low prices, how accessible (how far) is destination for him/her, how much is the price (and if priced too low, can this be a motivation for tourists?). Also important to identify is the degree of integration in the destination culture, especially in terms of certain consumer vulnerability, consequences and risks associated with the possibility of using private clinics versus state clinics, etc., and other items of purely personal interest (passports, visas, vaccines, other local standards, the risk of not getting better, etc.)

Setting objectives is the next step following market analysis. Since the creation and development of medical tourism products involves numerous supporters - Figure 4 - (healthcare, accommodation, meal, transportation, entertainment providers, etc.), setting objectives that correspond to the directions of development of each of these and then harmonising them to fulfil the common goal, unitary for the destination (to constitute as a medical tourism destination) is absolutely necessary and is quite a challenge for marketers. The lack of cooperation and harmonisation between different players, as well as the lack of a common vision and strategy (Lajos, V., 2014) was found among the supporters of medical tourism for the destination Romania, this also resulting from the lack of a unitary conception in terms of the development of the type of tourism/specific medical products. The diversity of supporters in tourism results from their very definition as "any group or individual who can affect or is affected by the achievement of a goal of a company" (Freeman, 1984), supporters of medical tourism being, next to the destination supporters, healthcare providers, institutions, insurers, advisory boards, special committees, associations, and recreation providers (www1.american.edu/ted/medicaltourism.htm) - Figure 4.

The importance of each supporter for the final product shows, in fact, that the development of medical tourism depends on the development of medical tourism companies - supporting the destination, such as: associations of medical tourism, medical travel agencies (Sobo, Herlihy \& Bicker, 2011), brokers, including virtual ones (Solomon, 2011), and others, but also other categories of supporters whose interests must be known, organised/reorganised, prioritised and harmonised. At the same time, medical 
tourism cannot develop independently, but only within health tourism and in a planned system to coordinate efforts of all supporters of the destination, especially in the case of a tourism and balneotherapy resort!

The development of strategies envisages formulating product, price, distribution, promotion, staff, partnership, packaging and programming strategies in a relational manner. It must have the purpose of building a common structure (due to the multitude of tourist products in a destination), which can become a "range of products under the same brand - that of the destination", in which the organisation for the management, and marketing of the destination must effectively manage all tourism products within it (in this case, considering the medical ones), forming an integrated concept (Cepoi, V., 2014) which constitutes, in fact, the main problem in the planning/marketing planning of a destination (region or country level) for medical tourism. Strategies developed must be take into account the coordinated interests of all supporters and unite all destination components within an effective marketing activity by creating an appropriate system (infrastructure, human resource development, product development, systems and technology, related industries), so as to satisfy and, moreover, exceed the expectations of tourists. Therefore, profile associations, such as the Romanian Association for Medical Tourism, must set goals, such as attracting programs and funding before grounding promotion strategies (e.g., promotion of medical tourism on all channels and active participation in international meetings aiming to promote medical tourism in Romania, etc.), distribution (e.g., raising programs to increase the availability of medical tourism, etc..) and partnership (e.g., contacting foreign collaborators, organising communication forums to enhance connectivity and educate patients, insurance companies, agencies, brokers, consultants and physicians, etc.).

The next steps in the marketing planning for medical tourism are those related to budgeting, marketing programs and activities to control and evaluate the entire process, also specific to each destinations.

Medical tourism development therefore is conditioned at destination level (type region or country) by strategic planning (including marketing planning), from anticipating growth trends (involving economic and social development on the interaction between various players in the microenvironment of the relevant destinations), identifying and taking advantage of the strengths of Romania to transform comparative advantages into supported competitive advantages, but also by the precise knowledge of the size and characteristics of the market for medical tourism in Romania.

The tools above require a proactive strategy, implemented by organisations that integrate the efforts of all supporters to fill that/those market position(s) that the destination Romania has as objective!

However, the general problems derived from the complexity of the phenomenon related to the perceived quality of medical tourism services are enhanced by specific problems, such as the expected degree of safety, and increased degree of risk (not only from the interaction of supporters, but also by the stakes of medical tourism products health, integrity or even life of potential consumers). Also, "the sequence of medical tests and the interpretation of clinical results" in terms of a "continuum of medical services/benefits" - a responsibility of the entire value chain can generate major problems in the collaboration, accreditation and ensuring of privacy and confidentiality.

Thus, a destination "ready" with all the above for a successful medical tourism involves identifying the profitable market segments/niches (of course, with their deep 
understanding), going even to the development of a medical tourism brand, and then, obviously, raising awareness/communicating the intended benefits to the target audience. Moreover, given that medical tourism falls into health tourism, maximising potential consumer satisfaction may have its roots in the consumption of tourism products resulting from the synergy of types of tourism, under the umbrella of health tourism.
In conclusion, medical tourism in Romania cannot develop without the help of all supporters of the tourism destination, and can achieve competitive advantages only after a planned systemic approach which takes into account: a) balneotherapy tourism as a bridge to launch medical tourism, b) medical tourism as an extension of balneotherapy tourism creativity, or c) medical tourism as a pillar of health tourism.

Figure 1

\section{Structure (levels) of the tourism product for medical tourism in the case of tourism and balneotherapy resorts}
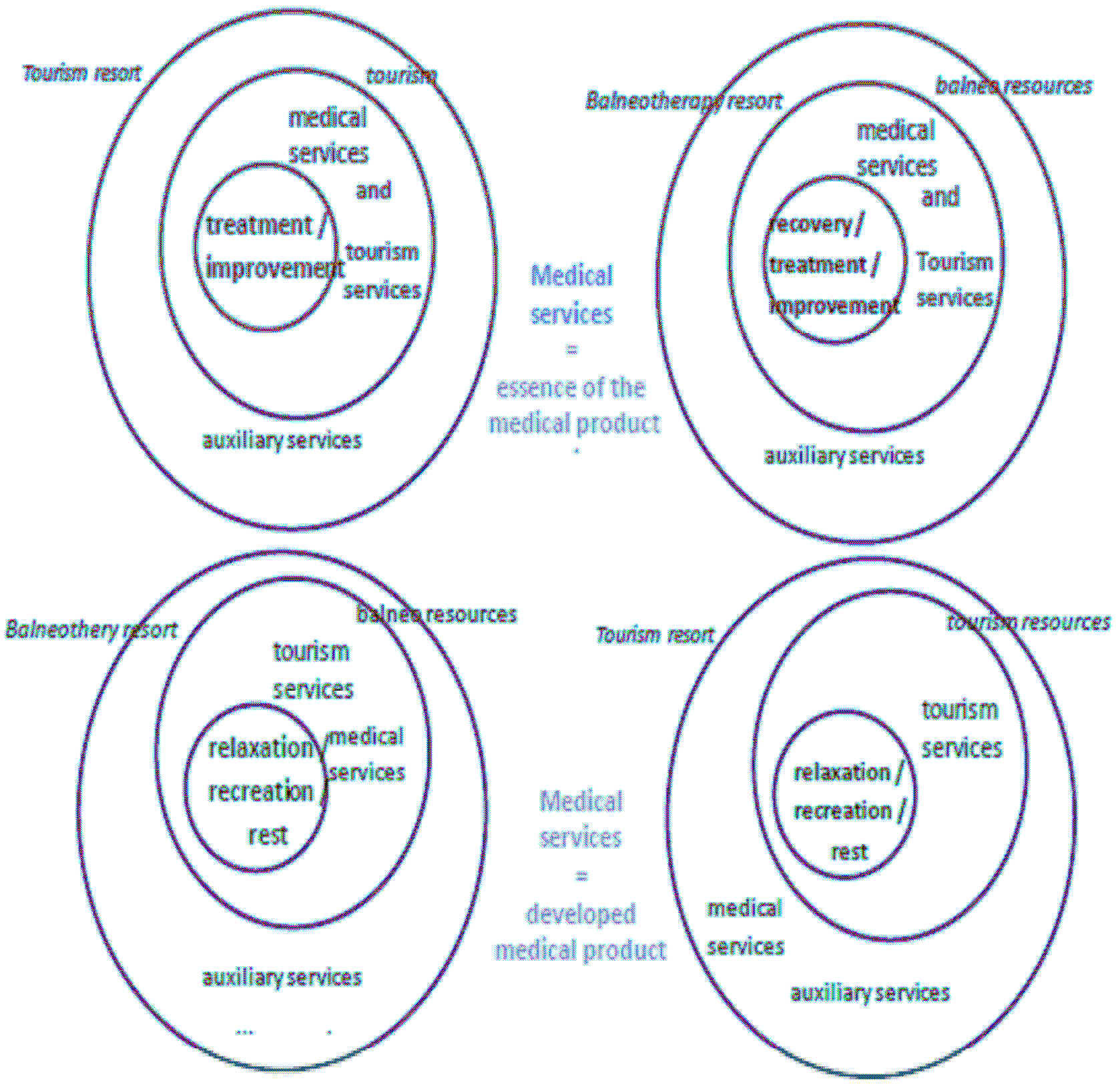
Figure 2

Structure (levels) of the tourism product for medical tourism in the case of a locality
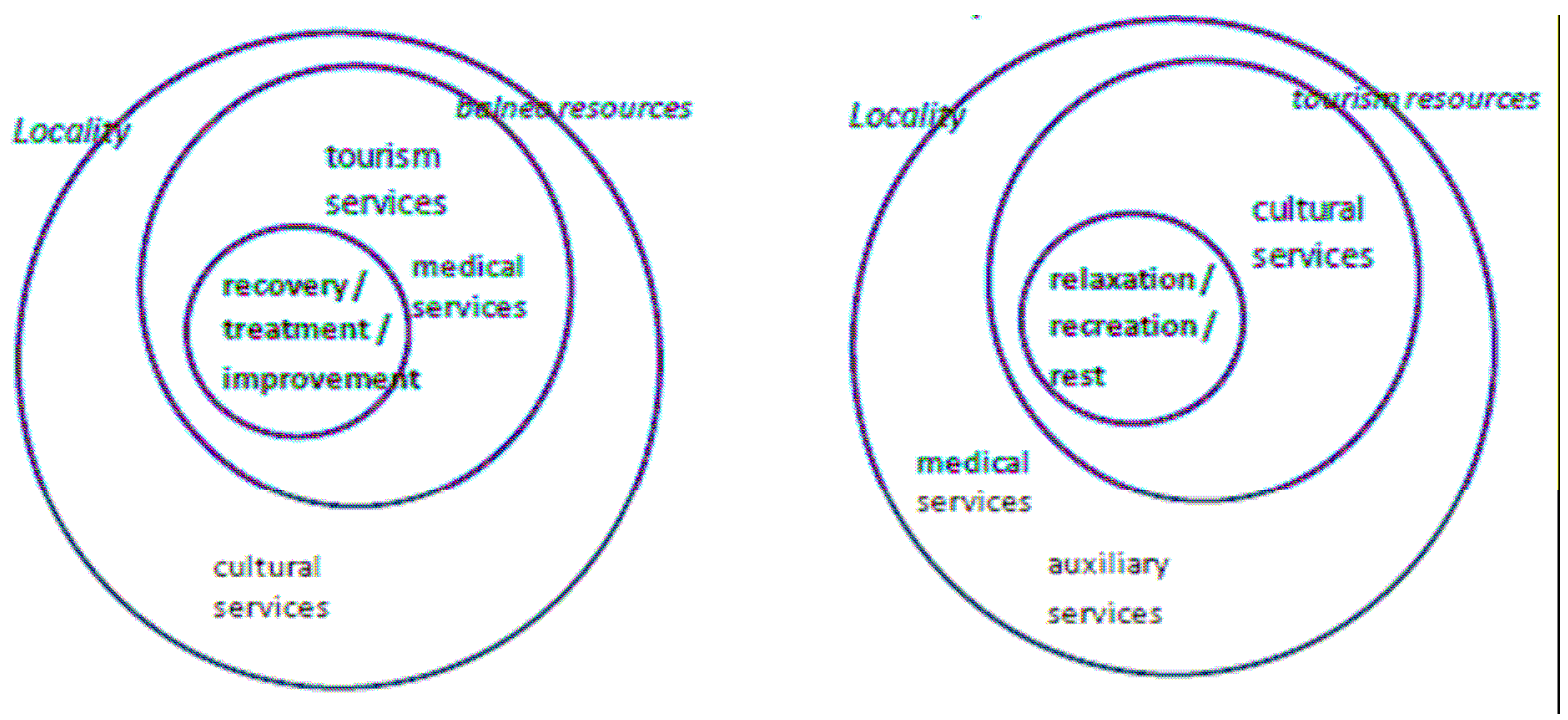

Figure 3

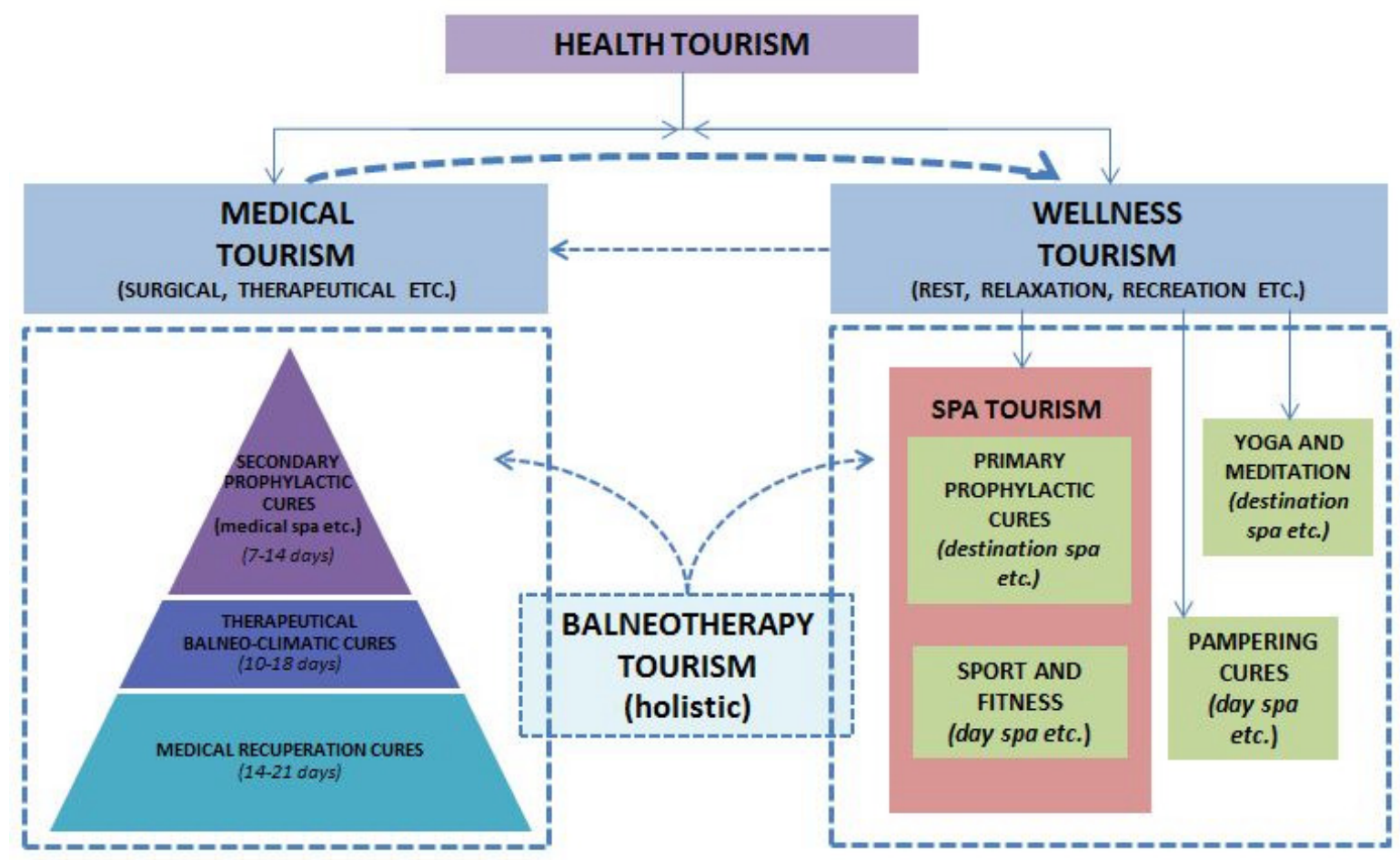

Dimensions of health tourism

Source: Stăncioiu, Băltescu, Botoş, Pârgaru (2013) 


\section{Figure 4}

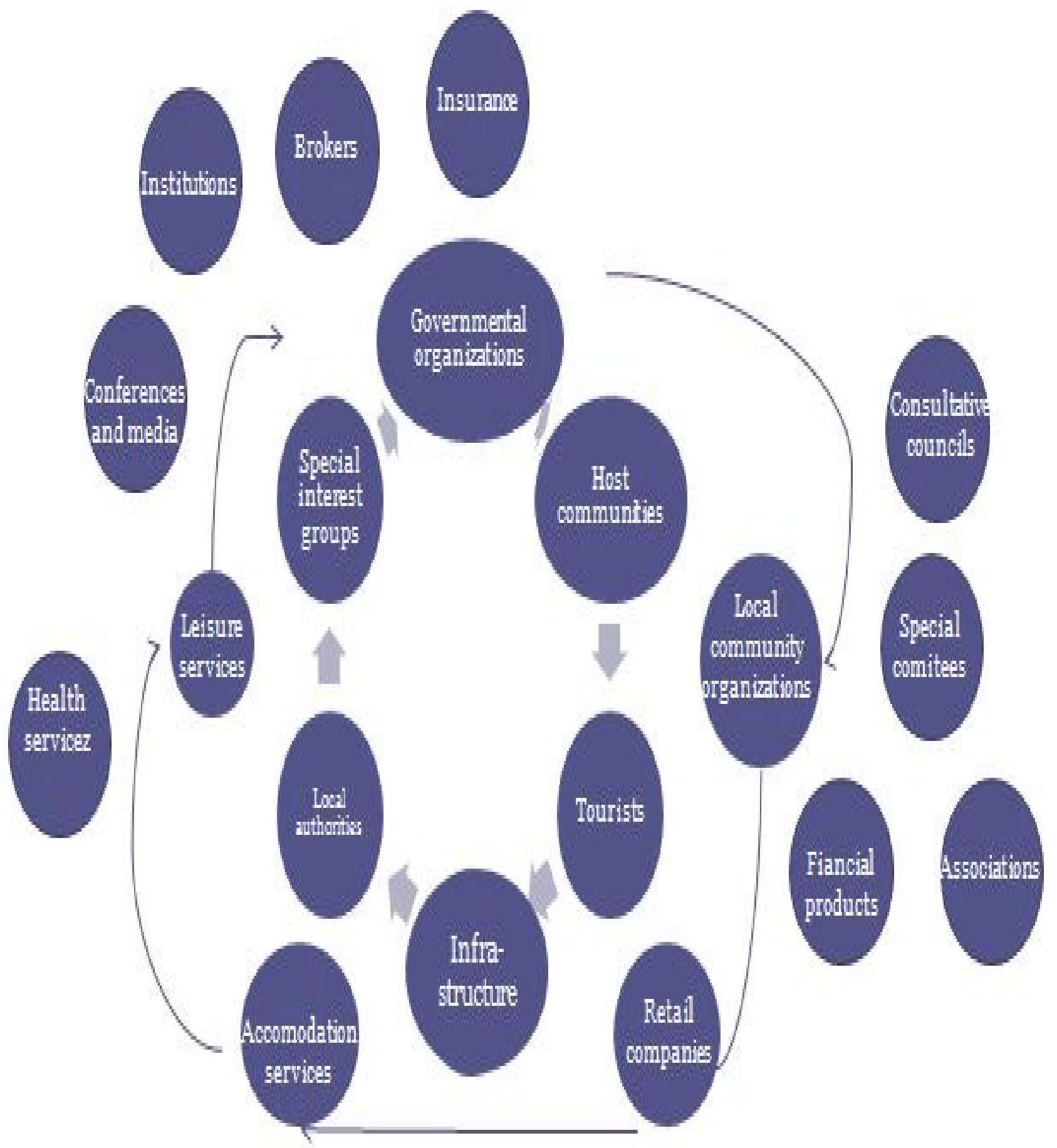

Map of supporters of a medical tourism destination

Source: after Freeman, 1984; Lunt, 2011; www.american.edu

Table 1 
Situation of healthcare facilities in Romania

\begin{tabular}{lll}
\hline & 2010 & 2011 \\
\hline Hospitals & 503 & 464 \\
\hline $\begin{array}{l}\text { Outpatient clinics integrated in hospitals and specialised outpatient } \\
\text { clinics }\end{array}$ & 472 & 414 \\
\hline Polyclinics & 311 & 262 \\
\hline Medical clinics & 204 & 187 \\
\hline Healthcare centres & 40 & 18 \\
\hline Mental health centres & 86 & 86 \\
\hline TB sanatoria & 4 & 2 \\
\hline Balneotherapy sanatoria & 9 & 9 \\
\hline Preventoria & 4 & 2 \\
\hline Health and social units & 68 & 64 \\
\hline Diagnostic and treatment centres & 26 & 29 \\
\hline Specialised medical centres & 188 & 221 \\
\hline General medicine practices & 1000 & 990 \\
\hline Medical practices in schools & 1235 & 1312 \\
\hline Medical practices for students & 52 & 54 \\
\hline Family medicine practices & 1117 & 11211 \\
\hline Medical firms & 0 & \\
\hline Dental practices & 110 & 118 \\
\hline Dental practices in schools & 1203 & 12613 \\
\hline Dental practices for students & 6 & \\
\hline Dental firms & 424 & 433 \\
\hline Specialised medical practices & 29 & 28 \\
\hline Specialised medical firms & 159 & 171 \\
\hline Pharmacies & 8870 & 9452 \\
\hline Pharmaceutical locations & 218 & 226 \\
\hline Pharmaceutical warehouses & 6682 & 6969 \\
\hline Nurseries & 1244 & 1324 \\
\hline Dental laboratories & 317 & 286 \\
\hline Blood establishments & 289 & 295 \\
\hline Other types of medical practices & 2978 & 3008 \\
\hline
\end{tabular}

Source: National Institute of Statistics, www.insse.ro, accessed on March 18, 2014 
Situation of healthcare professionals in Romania

\begin{tabular}{lll}
\hline & $\mathbf{2 0 1 0}$ & $\mathbf{2 0 1 1}$ \\
\hline Physicians & $\mathbf{5 2 2 0 4}$ & $\mathbf{5 2 5 4 1}$ \\
\hline of which: women & 36151 & 36261 \\
\hline Inhabitants per physician & 411 & 406 \\
\hline Physicians per 10,000 inhabitants & 24.4 & 24,6 \\
\hline Dentists & $\mathbf{1 2 9 9 0}$ & $\mathbf{1 3 3 5 5}$ \\
\hline of which: women & 8381 & 8720 \\
\hline Inhabitants per dentist & 1650 & 1599 \\
\hline Dentists per 10,000 inhabitants & 6.1 & 6,3 \\
\hline Pharmacists & $\mathbf{1 3 6 2 4}$ & $\mathbf{1 4 5 7 5}$ \\
\hline of which: women & 12410 & 13132 \\
\hline Inhabitants per pharmacist & 1573 & 1465 \\
\hline Pharmacists per $\mathbf{1 0 , 0 0 0}$ inhabitants & 6.4 & 6,8 \\
\hline Junior medical staff & $\mathbf{1 2 6 6 5}$ & $\mathbf{1 2 5 9 9 2}$ \\
\hline of which: women & $\mathbf{6}$ & \\
\hline Inhabitants per junior staff member & 11535 & 114812 \\
\hline Junior staff member per $\mathbf{1 0 , 0 0 0}$ inhabitants & 2 & \\
\hline Junior staff per physician & 169 & 169 \\
\hline Auxiliary medical staff & 59.1 & 59,0 \\
\hline of which: women & 2.4 & 2.4 \\
\hline
\end{tabular}

Source: National Institute of Statistics, www.insse.ro, accessed on March 18, 2014 


\section{Selective references}

Connell, J., (2013), Contemporary medical tourism: Conceptualisation, culture and commodification, Tourism Management, Vol.34, pp. 1-13

Holloway, J. C., (2004), Marketing for Tourism 4th Edition, Pearson Education Limited, Essex

Smith, M. Puczkó, L. (2009). Health and Wellness Tourism, Elsevier, Great Britain

Stăncioiu, A.-F. (2004). Strategii de marketing în turism, Editura Economică, Bucureşti

Stăncioiu A.-F., Botoş, A., Pârgaru, I. (2013), Produsul balnear balcanic - o abordare din perspectiva marketingului, Economie teoretică şi aplicată, Volumul XX, No. 10 (587), pp. 4-21

Stăncioiu, A.-F., Băltescu, C.-A., Botoş, A., Pârgaru, I. (2013), Aspecte conceptuale ale marketingului în turismul balnear din România, Economie teoretică şi aplicată Volumul XX, No. 2(579), pp. 124-137

Teleki, N., Munteanu, L. (2012). Spa Tourism in Romania Balneo-Turistică, Editura Royal Company

Teleki, N., Stoicescu, C., Teodoreanu, E., Grigore, L. (1984). Cura balneoclimatică în România, Editura SportTurism, Bucureşti 